\title{
Role of mifepristone in pre-induction cervical ripening: a double blind placebo-controlled study
}

\author{
Sandeep Sood ${ }^{1 *}$, Bhupesh Kumar Goyal ${ }^{2}$, Navpreet Kaur ${ }^{3}$
}

\begin{abstract}
${ }^{1}$ Department of Obstetrics and Gynaecology, Military Hospital, Chennai, Tamilnadu, India
${ }^{2}$ Department of Obstetrics and Gynaecology, Command Hospital Southern Command, Pune, Maharashtra, India

${ }^{3}$ Department of Pharmacology, Gian Sagar Medical College and Hospital, Rajpura, Patiala, Punjab, India
\end{abstract}

Received: 10 November 2021

Revised: 01 December 2021

Accepted: 02 December 2021

\author{
*Correspondence: \\ Dr. Sandeep Sood, \\ E-mail: drssigmc1988@gmail.com
}

Copyright: ( ) the author(s), publisher and licensee Medip Academy. This is an open-access article distributed under the terms of the Creative Commons Attribution Non-Commercial License, which permits unrestricted non-commercial use, distribution, and reproduction in any medium, provided the original work is properly cited.

\section{ABSTRACT}

Background: Mifepristone has been used for cervical priming and labour induction for long with modest success. This double-blind study compares mifepristone with placebo in causing cervical ripening and inducing spontaneous labour in women past their expected date of delivery.

Methods: 200 women at 40 weeks gestation received mifepristone or placebo after Bishop score was assessed. 48 hours later, cervical score was rechecked. Improvement in Bishop score was noted as primary outcome measure. Incidence of spontaneous labour, cesarean delivery and meconium staining of liquor during labour was also monitored.

Results: 16 women went into labour before 48 hours and 184 were evaluable. Improvement in Bishop score was noted in significantly more women in mifepristone group (82/94 versus 42/90, $\mathrm{p}<0.0001)$. Mean change in Bishop score was 3.22 in mifepristone group and 1.61 in placebo group. This advantage in cervical ripening with mifepristone did not translate into better obstetric outcome. The incidence of spontaneous labour (64/94 mifepristone versus $60 / 90$ placebo), cesarean section (4/94 versus 12/90) and MSL (8/94 versus 10/90) was comparable in the two groups and did not reach statistical significance.

Conclusions: Mifepristone has a beneficial effect on cervical ripening in term pregnancies but does not offer obstetric advantage in terms of higher rates of spontaneous labour or vaginal delivery.

Keywords: Cervical ripening, Mifepristone, Labour induction, Bishop score

\section{INTRODUCTION}

Ever since its development by Roussel in 1982, mifepristone has been used for approved or off-label indications in obstetrics. ${ }^{1,2}$ The most common, and FDAapproved, indication for its use remains induction of abortion in the early first trimester. The other off-label, but evidence-based, indications for its use in obstetric practice include management of second-trimester abortions, where pretreatment with mifepristone causes favorable cervical changes before misoprostol administration (in medical abortions) or D and $\mathrm{E}$ (in surgical abortions) and management of intrauterine fetal demise in second-and third-trimesters. The usefulness of mifepristone in cervical ripening and labor induction has been reported by several studies since $1992 .{ }^{3-10}$ Frydman et al first reported that mifepristone-treated term pregnancies were significantly more likely to go into spontaneous labor or present a ripe cervix for labour induction. ${ }^{3}$ Kayastha et al reported similar benefits in post-cesarean pregnancies where labour induction was indicated. ${ }^{4}$ Stenlund et al also found mifepristone, used in 
$400 \mathrm{mg}$ dose compared to $200 \mathrm{mg}$ used by Frydman et al gave equally encouraging results for cervical ripening and labour induction. ${ }^{7}$ Many other studies by Wing et al and McGill et al have shown beneficial effects from use of mifepristone without any adverse effects on the mother or the neonate. ${ }^{89}$ Berkane et al however, were unable to demonstrate any improvement in obstetric outcome with varying doses of mifepristone (from 50-600 $\mathrm{mg}$ ) compared with placebo. ${ }^{10}$ Hapangama et al in 2014 reviewed the role of mifepristone in labour induction and concluded that there is insufficient evidence to support the use of mifepristone for labour induction though they did make a note of the fact that incidence of cesarean section for failed induction seemed less in mifepristone treated women. In the only study published from India, Yeliker et al reported modest improvement in cervical ripening when mifepristone was given 24 hours before starting misoprostol administration. ${ }^{11,12}$ Despite the available evidence that supports the use of mifepristone for cervical priming and labour induction at term, mifepristone is not being used routinely as an adjuvant for labour induction. ${ }^{3-10}$ Not many studies on its role in cervical priming/labour induction have been published since review by Hapangama et al despite their call for more research to elucidate the role of mifepristone for this indication further. In this study, we compared mifepristone with placebo among women whose pregnancies had passed their estimated due date (EDD) and who were scheduled for labour induction at 41 weeks, on higher rates of favorable cervix and more possibilities of spontaneous labour.

\section{METHODS}

This was a double blind placebo controlled randomized control study conducted at a tertiary care Central Command hospital based in Central India between January till December 2018 after obtaining clearance from the institutional ethics committee. Flow chart of the study prepared (Figure 1).

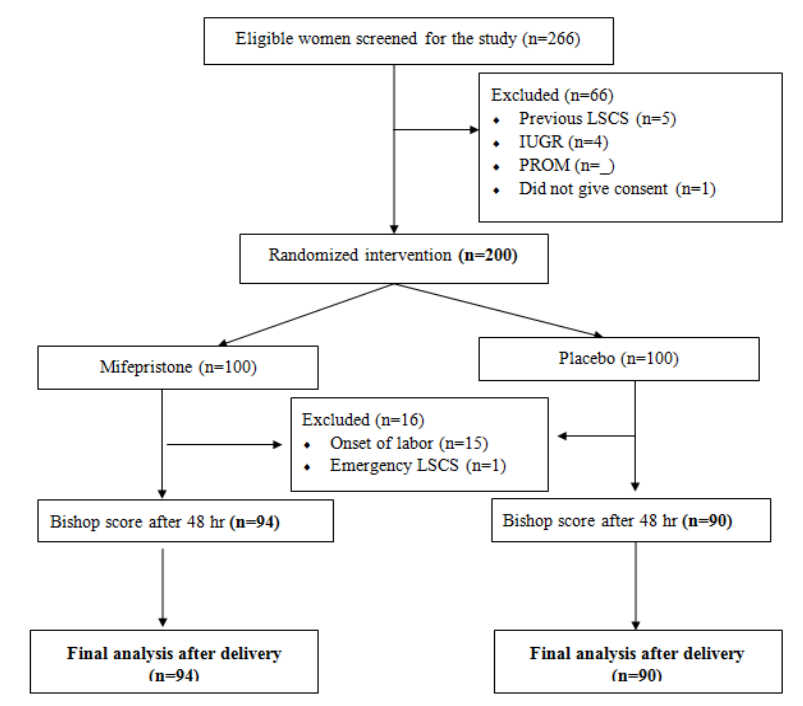

Figure 1: Flow diagram of the study.
Two hundred eligible women who crossed their EDD without any signs of labour were enrolled who met the inclusion criteria including gestational age between 40 weeks and 40 weeks 2 days, singleton uncomplicated pregnancy, normal fetal growth, primi- or multigravida, and an unscarred uterus. Exclusion criteria included any indication for elective cesarean section, fetal growth restriction or macrosomia, PROM, chorioamnionitis, or any concomitant medical disorders of the mother. Patients who went into labour before the minimum 48 hours period for studying the effect of the intervention were enrolled but not analyzed into the study. Informed consent was taken after the intervention was explained to women. Bishop's score was assessed by one of the two senior gynecologists. Computer-generated randomization, and allocation concealment through serial labeled opaque envelopes lying with incharge, who was not part of the research team. The double blinded intervention (mifepristone $200 \mathrm{mg}$ or placebo calcium gluconate 500 mg packed into identical tablets by hospital pharmacy) was administered by a trained staff nurse who was not part of the research team. After 48 hours, cervical status was reassessed by the same gynecologist who checked the cervix earlier to eliminate inter-observer bias. Change in cervical parameters after 48 hours, if any, was duly noted. We waited for women to go into spontaneous labour during the next 96 hours. Those who did not go into labour till 40 weeks 6 days were given labour induction as per the existing institutional protocol that consists of two intracervical doses of dinoprostone gel $0.5 \mathrm{mg}$ six hours apart, followed by oxytocin infusion, starting at $5 \mathrm{mU} / \mathrm{min}$ and increasing by the same amount every 30 minutes till adequate uterine activity is achieved. The primary outcome measure of this study was an improvement in Bishop score with mifepristone compared with placebo assessed at 48 hours after administration of the intervention. The secondary outcome measures were; incidence of spontaneous labour, the incidence of cesarean section, and incidence of meconium staining of liquor amnii during labour. Data was decoded at the end of the study and presented as mean, standard deviation (SD). For $90 \%$ power, a $95 \%$ confidence level and alpha error below 5\%, the sample size was calculated based upon the previous studies where a $20 \%$ significant change in the Bishop score was observed with mifepristone. ${ }^{8,9}$ It was estimated that a minimum of 85 patients in each group would be required, hence, we included total of 200 patients (100 in each group) in our study, assuming $10 \%$ will be excluded having entered labour within 48 hours of intervention could not be analyzed. Discrete data was analyzed statistically using Fisher's test and continuous data using ' $t$ ' test on graph pad software.

\section{RESULTS}

A total of 200 women were enrolled in the study. Fifteen women who went into labour before the mandatory 48 hours of administration of the intervention (six in the mifepristone group and five in the placebo group) were 
not analyzed. One woman had emergency LSCS for fetal distress due to cord prolapse within 48 hours and was also excluded. A total of 184 women were evaluable, 94 in the mifepristone group and 90 in the placebo group. The study population in the two groups was well-matched for age, gravidity, parity and period of gestation (Table 1). Sixty-two of $94(65.9 \%)$ in the mifepristone group and 58 of $90(64.4 \%)$ in the placebo group were primigravidae. Mean Bishop score at the time of administering intervention in both groups was also comparable, 2.93 in mifepristone group and 2.70 in the placebo group. The cervical score was rechecked after 48 hours in all evaluable cases. Favorable change in Bishop score was seen significantly more often in the mifepristone group than the placebo group (Table 2). Improvement in Bishop score was noted in 82/94 (87.2\%) women in the mifepristone group compared to only $42 / 90$ $(46.7 \%)$ in the placebo group. This difference was significant statistically $(\mathrm{p}<0.0001)$.

Table 1: Patient characteristics.

\begin{tabular}{|llll|}
\hline Parameters & Mifepristone & Placebo & $\begin{array}{l}\text { P } \\
\text { value }\end{array}$ \\
\hline Age (years) & $26.4 \pm 7.2$ & $25.3 \pm 6.3$ & 0.27 \\
\hline Gravidity & $1.60 \pm 0.5$ & $1.70 \pm 0.5$ & 0.17 \\
\hline Parity & $0.44 \pm 0.1$ & $0.43 \pm 0.1$ & 0.49 \\
\hline Gestational age & $40 \mathrm{w} \mathrm{1} \mathrm{d}$ & $40 \mathrm{w} \mathrm{1} \mathrm{d}$ & $\mathrm{NS}$ \\
\hline $\begin{array}{l}\text { Mean Bishop } \\
\text { Score before } \\
\text { intervention }\end{array}$ & $2.93 \pm 1.4$ & $2.70 \pm 1.6$ & $\mathrm{NS}$ \\
\hline
\end{tabular}

The mean change in the Bishop score was 3.22 in the mifepristone group and was 1.61 in the placebo group. These changes in Bishop score were evenly distributed amongst primi and multi-parous women. Though the mifepristone group showed a much higher incidence of favourable cervical change compared to placebo, this difference did not translate into any obstetric advantage. The incidence of spontaneous labour in the two arms of the study was comparable (Table 2).

Table 2: Study outcome.

\begin{tabular}{|llll|}
\hline Parameters & $\begin{array}{l}\text { Mifepristone } \\
(\mathbf{N}=94)\end{array}$ & $\begin{array}{l}\text { Placebo } \\
(\mathbf{N}=90)\end{array}$ & P value \\
\hline $\begin{array}{l}\text { Bishop score } \\
\text { improved }\end{array}$ & 82 & 42 & $<0.0001$ \\
\hline $\begin{array}{l}\text { Mean change } \\
\text { in Bishop } \\
\text { score }\end{array}$ & $3.22 \pm 2.15$ & $1.61 \pm 2.11$ & $<0.0001$ \\
\hline $\begin{array}{l}\text { Spontaneous } \\
\text { labour }\end{array}$ & 64 & 60 & 0.87 \\
\hline $\begin{array}{l}\text { Vaginal } \\
\text { delivery }\end{array}$ & 90 & 78 & 0.036 \\
\hline $\begin{array}{l}\text { Cesarean } \\
\text { section }\end{array}$ & 4 & 12 & 0.036 \\
\hline MSL & 8 & 10 & 0.62 \\
\hline
\end{tabular}

Total $64 / 94(68.1 \%)$ women in the mifepristone group and 60/90 (66.7\%) women in the placebo group went into spontaneous labour in the next four days $(p=0.88)$. Women who went into spontaneous labour were further stratified in four groups based on the time interval; 48-72 hours, 72-96 hours, 96-120 hours, and 120-144 hours. There was no difference between the two groups (Table 3 ). Thirty women in each group required labour induction as they did not go into labour till 40 weeks 6 days. Overall, a greater proportion of women in the mifepristone group delivered vaginally (90/94 in mifepristone group versus 78/90 in placebo group) but the difference did not reach statistical significance $(\mathrm{p}=0.036)$. The incidence of meconium staining of the liquor was also comparable in the two groups (Table 2).

Table 3: Onset of spontaneous labour.

\begin{tabular}{|llll|}
\hline $\begin{array}{l}\text { Time after } \\
\text { intervention } \\
\text { (hours) }\end{array}$ & Mifepristone & Placebo & P value \\
\hline $\mathbf{4 8 - 7 2}$ & 29 & 26 & NS \\
\hline $\mathbf{7 2 - 9 6}$ & 12 & 8 & NS \\
\hline $\mathbf{9 6 - 1 2 0}$ & 17 & 17 & NS \\
\hline $\mathbf{1 2 0 - 1 4 4}$ & 6 & 9 & NS \\
\hline
\end{tabular}

\section{DISCUSSION}

Women in India get very nervous when their pregnancies cross the EDD without any signs of impending labour. We call this situation 'pastdatism', to distinguish it from 'postdatism', a term used interchangeably with post-term pregnancies. In our institution, labour induction for these women with otherwise uncomplicated pregnancies is done at 41 weeks $( \pm 1$ day). Some women do go into labour spontaneously during the week following EDD leaving a few for labour induction. Not intervening with labour induction earlier than 41 weeks affords better chances of vaginal delivery in our hospital. Considering mifepristone with its antiprogestogen action has been shown to increase cervical ripeness in various studies published earlier, we decided to study whether administration of mifepristone in the management scheme of these women with 'pastdatism' will have any beneficial effect in earlier onset of labour and faster delivery. ${ }^{3-10}$ Therefore, we administered mifepristone (or placebo) to these women as soon as they crossed their EDD. We hoped that mifepristone would make more women have favourable cervices, resulting in higher rates of spontaneous labour or greater chances of successful labour induction (and therefore lower cesarean delivery rates). In our study, we chose to assess the action of mifepristone on cervical ripeness after 48 hours. Cervical ripening is a biochemical change that is likely to take at least 48 hours following oral administration of mifepristone, the anti-progestational drug that will work through a complex cascade of biochemical changes. Even Frydman et al assessed the cervical score on $4^{\text {th }}$ day after giving mifepristone on two successive days. Certain other investigators have waited for only 24 hours after 
mifepristone administration before giving labour induction with misoprostol. ${ }^{3-8}$ At the end of 24 hours, there was no difference in the median Bishop score between the mifepristone and placebo group. Wing et al had speculated that longer exposure to mifepristone might be required to show a significant clinical difference in cervical ripening. ${ }^{8}$ Twenty-four hours duration appears too short for the complex biochemical change in the cervix to happen. For first-trimester medical abortions, misoprostol is best administered after 48 hours of mifepristone for maximum success. Our placebocontrolled double-blind study has shown that mifepristone does bring about more favourable cervical changes than placebo in prolonged pregnancies. Similar results regarding cervical changes with mifepristone have been reported by several other investigators in their studies in the past. ${ }^{3-10,12}$ However, we were unable to demonstrate a beneficial effect of mifepristone on the incidence of spontaneous onset of labour in our population unlike other studies. A meta-analysis by Hapangama et al on role of mifepristone for labour induction also concluded that available data are insufficient to support the use of mifepristone to induce labour ${ }^{11} \mathrm{We}$ found no difference in the incidence of spontaneous labour between women treated with mifepristone or with placebo. Two-thirds of women in each group went into spontaneous labour and when the data was stratified based on the time interval following administration of mifepristone/placebo (Table 3), there was no significant difference between the two groups. It is pertinent to note here that Berkane et al also could not show significant benefit from use of mifepristone in the rate of spontaneous labour. ${ }^{10}$ Incidence of cesarean section appeared to be more in the placebo group compared to mifepristone group, but the difference did not reach statistical significance. This finding of our study is in keeping with the results of other studies also.

\section{CONCLUSION}

To conclude, though we did get some beneficial effect of mifepristone on cervical score in women past their EDD in our study, we were unable to demonstrate any advantage of mifepristone in inducing labour among our population or shorten the intervention-delivery interval or result in more successful induction of labour with improvement in vaginal delivery rates. Future trials may consider larger number of patients with the higher dose of mifepristone $(400 \mathrm{mg}$ ) to further clarify the role of mifepristone in labour induction process.

Funding: No funding sources Conflict of interest: None declared

Ethical approval: The study was approved by the Institutional Ethics Committee

\section{REFERENCES}

1. Philibert D, Deraedt R, Teutsch G, Tournemine C, Skiz E. A new lead for steroid anti-hormones. Available at: https://www.endocrine.org/news-andadvocacy/news-room/endo-annual-meeting. Accessed on 20 September 2021.

2. Dzuba IG, Grossman D, Schreiber CA. Off-label indications for mifepristone in gynecology and obstetrics. Contraception. 2015;92:203-5.

3. Frydman R, Lelaidier C, Baton-Saint-Mleux C, Fernandez H. Labour induction in women at term with mifepristone (RU-486): a double-blind, randomized, placebo-controlled study. Obstet Gynecol. 1992;80:972-5.

4. Kayastha S, Mainali S, Subedi R. Efficacy Study of Mifepristone in Pre-induction Cervical Ripening and Induction of Labour. Nepal Med Coll J. 2021;23(3): 259-63

5. Hcini N, Jolivet A, Pomar L, Mchirgui A, Maamri F, Elcadhi Y, Lambert V, Carles G. Cervical maturation using mifepristone in women with normal pregnancies at or beyond term. Eur J Obstet Gynecol Reprod Biol. 2020;248:58-62.

6. Ghimire A, Gurung G, Ojha BP, Baral J. Effectiveness of Mifepristone plus Misoprostol and Misoprostol alone in Cervical Ripening and Induction of Labour in Postdated Pregnancy. Nepal Med Coll J. 2020;15(2):45-9.

7. Stenlund PM, Ekman G, Aedo A, Bygdeman M. Induction of labor with mifepristone - A randomized, double blind study versus placebo. Acta Obstet Gynecol Scand. 1999;78: 793-8.

8. Wing DA, Fassett MJ, Mishell DR. Mifepristone for preinduction cervical ripening beyond 41 weeks' gestation: A randomized controlled trial. Obstet Gynecol. 2000;96: 543-8.

9. McGill J, Shetty A. Mifepristone and misoprostol in the induction of labor at term. Int J Obstet Gynecol. 2007;96:80-4.

10. Berkane N, Verstraete L, Uzan S, Boog G, Maria B. Use of mifepristone to ripen the cervix and induce labor in term pregnancies. Am J Obstet Gynecol 2005; 192:114-20.

11. Hapangama D, Neilson JP. Mifepristone for induction of labour. Cochrane Database Syst Rev. 2009;3: CD002865.

12. Yelikar K, Deshpande S, Deshpande R, Lone D. Safety and efficacy of oral mifepristone in preinduction cervical ripening and induction of labour in prolonged pregnancy. J Obstet Gynaecol India. 2015; 65(4):221-5.

Cite this article as: Sood S, Goyal BK, Kaur N. Role of mifepristone in pre-induction cervical ripening: a double blind placebo-controlled study. Int J Reprod Contracept Obstet Gynecol 2022;11:110-3. 